\title{
Application of Bradford's Law of Scattering to the Scientific Publications of Energy and Environment Research
}

\author{
Chandran Velmurugan ${ }^{1 *}$, Natarajan Radhakrishnan ${ }^{2}$
}

${ }^{1}$ Research Scholar, Department of Library and Information Science, Periyar University, Salem- 636011 , Tamilnadu, INDIA

${ }^{2}$ Associate Professor, Department of Library and Information Science, Periyar University, Salem- 636011 , Tamilnadu, INDIA

*Corresponding Contact:

Email: murugan73@gmail.com

\begin{abstract}
This study has been made an attempt to describe the one of the most essential bibliographic laws i.e. Bradford law of scattering to test the scholarly publications of energy and environment in Australia. A total of 2802 papers published, out which $83.4 \%$ were journal articles and $99.7 \%$ were in the English language. According to Australian research, the output of Environmental Sciences Ecology (13.807\%) account for the largest increase and it is occupied in the first place and Energy Fuels $(6.208 \%)$ is in the 6th place during the present study. The three most productive journals with high citations were 'Ecological Applications' ( $=4,2721$ citations), 'Astrophysical Journal' (= 44, 1614 citations), and 'Monthly notes of the Royal Astronomical Society' (= 38, 1389 citations) and the maximum number of citations contributed by 'BAZZAZ FA' from Harvard University, USA. In this study, based on the speculative aspects of Bradford's Law of Scattering is tested and identified that the ratio depicts that it does not fit into the Bradford's law of distribution.
\end{abstract}

Key words

Scientometrics, Bradford's Law, scholarly publications, energy and environment, Australian research, India, Australia

\section{INTRODUCTION}

To meet the energy requirements of supportable economic growth, policy makers, analysts, and corporate leaders have progressively referred to the role that energy and environment would perform. For that reason, this paper has taken into attention to find out the publications growth trends and development in the field of energy and environment research in Australia as indexed in the web of science. Some of the related works have already done in the field of 
energy and solar energy by various scientists (Tijssen 1992; Gupta 1980; Lawson, Kostrewsi \& Oppenheim 1980; Pouris \& Pouris 1987; ASSAF 2006). A numerous reviews of the research outputs on scientometrics as well as bibliometrics have already done including Bradford distribution. Here, we have identified some notable reviews of eminent scholars and researchers in different areas for the current study such as Bradford, 1934; Lawani, 1973; Brookes, 1977; Avramescu, 1980; Drott, 1981; Asai, 1981; Egghe, 1986, 1990; Tyagi, 1986; Qui, 1990; Gupta, 1991; Bandyopadhyay, 1999; Nicolaisen \& Hjorland, 2007. To enrich strength of this paper, researchers have taken into account a few from authors' previous study under different domain as well as solo journals of scientometric analysis for the present analysis such as research analysis on Biotechnology by Velmurugan and Radhakrishnan (2015), Journal of Information Literacy (2015), Quantitative Analysis of Scientific Publications Output on Engineering Journal (2015), Supply Chain Management (2015), Library Herald (2015), Pharmacognosy (2015), Scientometric observations on DESIDOC Journal of Library and Information Technology by Velmurugan and Radhakrishnan (2015), Journal of Intellectual Property rights by Velmurugan $(2013,2014)$, Annals of Library and Information Studies for the year 2007-2012 by Velmurugan (2013) Indian Journal of Pure and Applied Physics for the Year 2009 - 2012 by Velmurugan (2014), Technical Review Journal by Velmurugan (2014).

\section{ObJectives OF The Study}

This study demarcates the research with computing the energy and environment publication trends for the period between January 1989 and November 2015 indexed at Web of science database. The study involves a total of 2803 scientific literature output from 1199 journals with 64994 citations and 14546 authors by 85 various countries. The present study has been designed with the below purposes.

- To identify the growth analysis of energy and environment research output,

- To compare the Indian versus Australian literature outputs,

- To compare the Australia publications share and World literature outputs,

- To depict the highly cited authors of energy and environment research,

- To find out the core journals of energy and environment in Australia and

- To test the Bradford Law of Scattering

\section{Methodology AND Limitations}

To meet the objectives of the study, the web of science core collection database has been used with the keyword as 'energy and environment' has given in the topic and the period 1989 - 2015 and 2802 scientific papers published in 1199 journals in the English language were retrieved till November 2015 for further analysis. To evaluate the research outputs, tested using the Bradford's Law of Scattering for better results during the period of study. The present study is limited for the period of 26 years beginning from 1989 to 2015 (till November 2015) but the data have been retrieved as it is available in the database (started 2016). Hence, the whole data have taken into account and made specific observations based on the study in the Australia scenario with comparison of India and world output.

\section{Analysis AND Results}

\section{Growth rate of literature in Energy and Environment in India and Australia}

Table 1 represents that the research outputs of Energy and Environment in India and Australia during the period of study between 1989 and 2015. As far as the Indian literature concerns, the huge numbers of $353(12.7 \%)$ papers are produced in the 2015 on the other 
hand, the small numbers of papers are produced in the year 1989. It is found that the growth rate has been gradually increased in the year 1991 onwards. According to Australian outputs, the growth rate ratio is 21 papers in 1991 and 308 papers in 2015 with 1466\% increase. The maximum numbers of outputs are published in the year 2015 whereas the least number of research papers are published in 1991 and the average numbers of papers are 112.08 in Australia and the average numbers of papers are 102.89 in Indian literatures.

Table 1: Growth of publication

\begin{tabular}{|c|c|c|c|c|c|}
\hline \multirow{2}{*}{ S. No } & \multirow{2}{*}{ PY } & \multicolumn{2}{|c|}{ India } & \multicolumn{2}{c|}{ Australia } \\
\cline { 3 - 6 } & TR & TR $\%$ & TR & TR \\
\hline 1 & 1989 & 1 & 0.0 & - & - \\
\hline 2 & 1990 & 3 & 0.1 & - & - \\
\hline 3 & 1991 & 17 & 0.6 & 21 & 0.7 \\
\hline 4 & 1992 & 24 & 0.9 & 28 & 1.0 \\
\hline 5 & 1993 & 26 & 0.9 & 33 & 1.2 \\
\hline 6 & 1994 & 25 & 0.9 & 33 & 1.2 \\
\hline 7 & 1995 & 24 & 0.9 & 37 & 1.3 \\
\hline 8 & 1996 & 30 & 1.1 & 50 & 1.8 \\
\hline 9 & 1997 & 30 & 1.1 & 49 & 1.7 \\
\hline 10 & 1998 & 40 & 1.4 & 56 & 2.0 \\
\hline 11 & 1999 & 38 & 1.4 & 45 & 1.6 \\
\hline 12 & 2000 & 42 & 1.5 & 55 & 2.0 \\
\hline 13 & 2001 & 51 & 1.8 & 59 & 2.1 \\
\hline 14 & 2002 & 59 & 2.1 & 66 & 2.4 \\
\hline 15 & 2003 & 50 & 1.8 & 91 & 3.2 \\
\hline 16 & 2004 & 79 & 2.8 & 82 & 2.9 \\
\hline 17 & 2005 & 90 & 3.2 & 80 & 2.9 \\
\hline 18 & 2006 & 113 & 4.1 & 126 & 4.5 \\
\hline 19 & 2007 & 139 & 5.0 & 119 & 4.2 \\
\hline 20 & 2008 & 116 & 4.2 & 108 & 3.9 \\
\hline 21 & 2009 & 148 & 5.3 & 162 & 5.8 \\
\hline 22 & 2010 & 180 & 6.5 & 170 & 6.1 \\
\hline 23 & 2011 & 196 & 7.0 & 227 & 8.1 \\
\hline 24 & 2012 & 253 & 9.1 & 238 & 8.5 \\
\hline 25 & 2013 & 316 & 11.4 & 279 & 10.0 \\
\hline 26 & 2014 & 335 & 12.0 & 280 & 10.0 \\
\hline 27 & 2015 & 353 & 12.7 & 308 & 11.0 \\
\hline & Total & 2781 & 100 & 2802 & 100 \\
\hline
\end{tabular}

Note: PY- Publication year, TR- Total records, TRP- Total records percentage

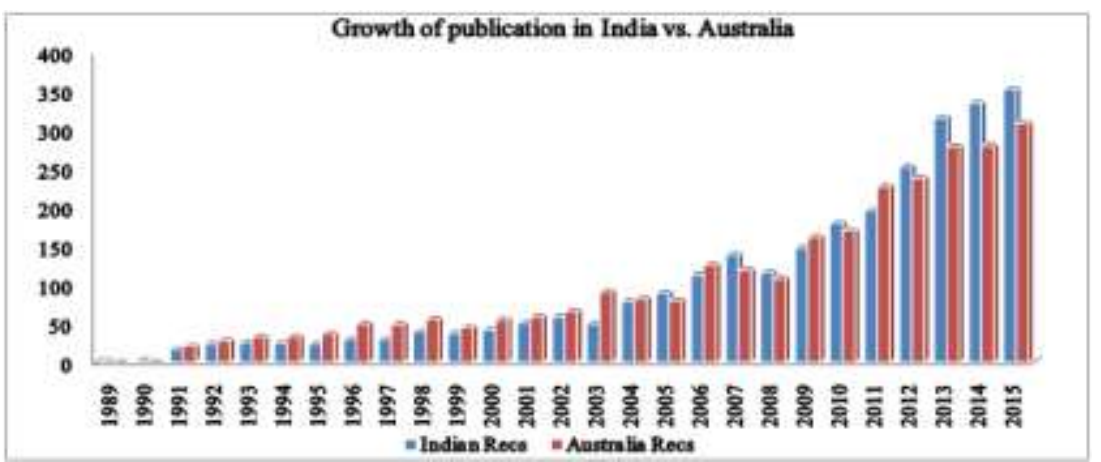

Figure 1: Growth of publication in India vs. Australia 


\section{Australia's publication share in world literature outputs}

Table 2 represents that the global publications share of Australia during 1991-2015 was 3.828183 which has gradually increased from 2.277657 in 1991 to 4.756022 in 2015 . This growth pattern could also be counted based on the journals increase via web of science database over the years. The maximum growth share is $4.75 \%$ in the year 2015 and followed $4.462355 \%$ in $2011,4.336338 \%$ in $2013,4.223936 \%$ in $2006,4.132607 \%$ in 2003 , and 4.035266 \% in 2012, whereas the least growth share in 1994 is $2.930728 \%$ and in the year 1991 is 2.27 percent. The results illustrate that the growth share of Australia and compare with world outputs during the period and indicates that the growth level is fluctuation trend.

Table 2: Australia's publication share in world literature outputs

\begin{tabular}{|c|c|c|c|c|}
\hline S. No & PY & ALO & WLO & Australia's Share \% \\
\hline 1 & 1989 & - & 43 & - \\
\hline 2 & 1990 & - & 126 & - \\
\hline 3 & 1991 & 21 & 922 & 2.28 \\
\hline 4 & 1992 & 28 & 911 & 3.07 \\
\hline 5 & 1993 & 33 & 998 & 3.31 \\
\hline 6 & 1994 & 33 & 1126 & 2.93 \\
\hline 7 & 1995 & 37 & 1149 & 3.22 \\
\hline 8 & 1996 & 50 & 1321 & 3.79 \\
\hline 9 & 1997 & 49 & 1335 & 3.67 \\
\hline 10 & 1998 & 56 & 1562 & 3.59 \\
\hline 11 & 1999 & 45 & 1583 & 2.84 \\
\hline 12 & 2000 & 55 & 1701 & 3.23 \\
\hline 13 & 2001 & 59 & 1752 & 3.37 \\
\hline 14 & 2002 & 66 & 1933 & 3.41 \\
\hline 15 & 2003 & 91 & 2202 & 4.13 \\
\hline 16 & 2004 & 82 & 2351 & 3.49 \\
\hline 17 & 2005 & 80 & 2604 & 3.07 \\
\hline 18 & 2006 & 126 & 2983 & 4.23 \\
\hline 19 & 2007 & 119 & 3322 & 3.58 \\
\hline 20 & 2008 & 108 & 3592 & 3.01 \\
\hline 21 & 2009 & 162 & 4163 & 3.89 \\
\hline 22 & 2010 & 170 & 4532 & 3.75 \\
\hline 23 & 2011 & 227 & 5087 & 4.46 \\
\hline 24 & 2012 & 238 & 5898 & 4.04 \\
\hline 25 & 2013 & 279 & 6434 & 4.34 \\
\hline 26 & 2014 & 280 & 7088 & 3.95 \\
\hline 27 & 2015 & 308 & 6476 & 4.76 \\
\hline & 1989-2015 & 2802 & 73194 & 3.83 \\
\hline
\end{tabular}

Note: PY- Publication year, ALO- Australia Literature Output, WLO- World Literature Output

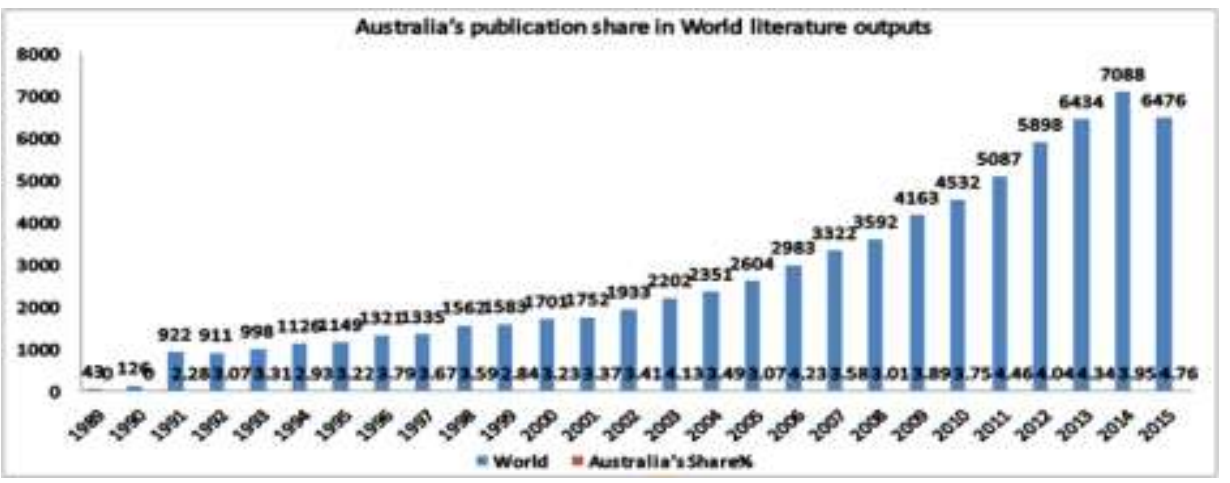

Figure 2: Australia's publication share in world literature outputs 


\section{Chronological distribution of publication in Australia}

Literature outputs are essential in every academic as well as research and development institutions. Here, Table 3 and figure 4 indicate we have evaluated the publication growth trend in the field of Energy and Environment Research, and the below table picture the total citations and annual citation per paper (ACPP) are measured during the study. Based on the outputs, the growth ratio range is from 0.80 to 1.58 and followed by the annual growth rate range is from 0.36 to 57.5. The citation range is from 263 in 2015 to 5674 in 2000 (figure 3). The most number of 308 (11.0\%) articles are published in 2015 and the small numbers of papers (21 papers) are produced in the begging year. the greatest number of annual average citation per paper is 53.05 in the year 2005 .

Table 3: Chronological distribution of publication

\begin{tabular}{|c|l|c|c|c|c|}
\hline S. No & PY & Recs & Percent & TC & ACPP \\
\hline 1 & 1991 & 21 & 0.7 & 974 & 46.38 \\
\hline 2 & 1992 & 28 & 1.0 & 936 & 33.43 \\
\hline 3 & 1993 & 33 & 1.2 & 1383 & 41.91 \\
\hline 4 & 1994 & 33 & 1.2 & 601 & 18.21 \\
\hline 5 & 1995 & 37 & 1.3 & 1145 & 30.95 \\
\hline 6 & 1996 & 50 & 1.8 & 1959 & 39.18 \\
\hline 7 & 1997 & 49 & 1.7 & 2460 & 50.20 \\
\hline 8 & 1998 & 56 & 2.0 & 1710 & 30.54 \\
\hline 9 & 1999 & 45 & 1.6 & 1708 & 37.96 \\
\hline 10 & 2000 & 55 & 2.0 & 5674 & 10.32 \\
\hline 11 & 2001 & 59 & 2.1 & 1807 & 30.63 \\
\hline 12 & 2002 & 66 & 2.4 & 2919 & 44.23 \\
\hline 13 & 2003 & 91 & 3.2 & 3608 & 39.65 \\
\hline 14 & 2004 & 82 & 2.9 & 3100 & 37.81 \\
\hline 15 & 2005 & 80 & 2.9 & 4244 & 53.05 \\
\hline 16 & 2006 & 126 & 4.5 & 3866 & 30.68 \\
\hline 17 & 2007 & 119 & 4.2 & 3830 & 32.18 \\
\hline 18 & 2008 & 108 & 3.9 & 3925 & 36.34 \\
\hline 19 & 2009 & 162 & 5.8 & 3870 & 23.89 \\
\hline 20 & 2010 & 170 & 6.1 & 3929 & 23.11 \\
\hline 21 & 2011 & 227 & 8.1 & 4581 & 20.19 \\
\hline 22 & 2012 & 238 & 8.5 & 3442 & 14.46 \\
\hline 23 & 2013 & 279 & 10.0 & 2134 & 7.65 \\
\hline 24 & 2014 & 280 & 10.0 & 926 & 3.31 \\
\hline 25 & 2015 & 308 & 11.0 & 263 & 0.85 \\
\hline & Total & 2802 & 100 & 64994 & 23.20 \\
\hline
\end{tabular}

PY - Publication year, TC - Total citations, ACPP- Average citation per paper

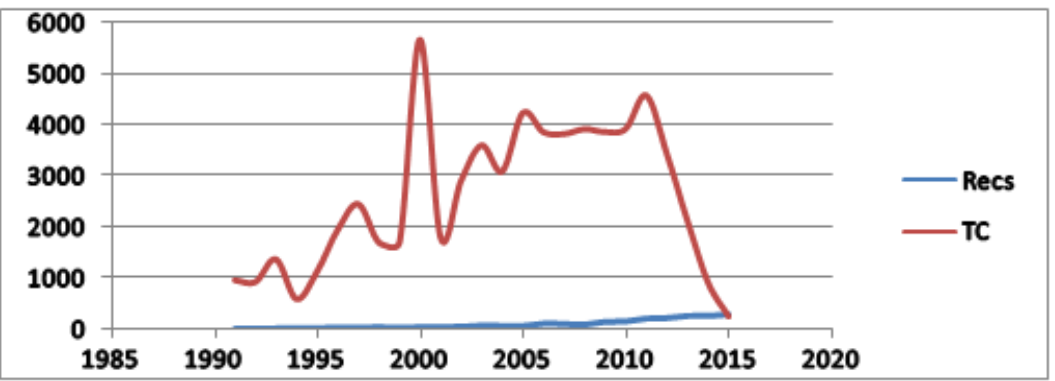

Figure 3: Chronological wise papers and citaions 


\section{Ranking of highly cited authors}

It can be observed form the Table 4 shows that the highly cited authors in the field of Energy and Environment Research in Australia during the period of study. The results reveal that a total of 64994 citations had contributed entire research outputs in the period of study. Out of that, more than 700 times cited papers of authors have collected for the present study. The maximum number of citations contributed by 'BAZZAZ FA' from Harvard University, USA, 'CLOUT $\mathrm{M}^{\prime}$ from University of Auckland, New Zealand, 'EVANS H' from England, 'LONSDALE WM' from CRC Weed Management System, Australia, 'MACK RN' from University of Tennessee, USA, 'SIMBERLOFF D' from CSIRO Entomology, Australia with 2667 citations with one paper who have occupied in the first rank respectively, and the lowest citations $(=1,708$ citations) is received by 'REKAS M' from University of New South Wales, Australia.

Table 4: Highly cited authors in Energy and Environment Research

\begin{tabular}{|c|c|c|c|c|}
\hline Rank & Author & Affiliation & TR & TC \\
\hline 1 & Bazzaz FA & Harvard University, Biological Labs, Cambridge, USA & 1 & 2667 \\
\hline 1 & Clout M & $\begin{array}{l}\text { University of Auckland, Scheme of Biological } \\
\text { Science, New Zealand }\end{array}$ & 1 & 2667 \\
\hline 1 & Evans H & CABI Bioscience, England. & 1 & 2667 \\
\hline 1 & Lonsdale WM & $\begin{array}{l}\text { CRC Weed Management System, Canberra, } \\
\text { Australia }\end{array}$ & 1 & 2667 \\
\hline 1 & Mack RN & $\begin{array}{l}\text { University of Tennessee, Dept Ecology \& } \\
\text { Evolution Biology, USA }\end{array}$ & 1 & 2667 \\
\hline 1 & Simberloff D & CSIRO Entomology, Canberra, ACT 2601, Australia & 1 & 2667 \\
\hline 2 & Swinburn BA & $\begin{array}{l}\text { Deakin University, Scheme of Health Science, } \\
\text { Melbourne, Australia }\end{array}$ & 6 & 1074 \\
\hline 3 & $\mathrm{Lu}$ GQ & $\begin{array}{l}\text { University of Queensland, Scheme of Chemical } \\
\text { Engineering, Brisbane, Australia }\end{array}$ & 4 & 914 \\
\hline 4 & Buyya R & $\begin{array}{l}\text { University of Melbourne, Dept Computer Science } \\
\text { \& Software Engineering, Australia }\end{array}$ & 8 & 795 \\
\hline 5 & Nowotny J & $\begin{array}{l}\text { Univ New S Wales, Scheme of Material Science \& } \\
\text { Engineering, Sydney, Australia }\end{array}$ & 7 & 770 \\
\hline 6 & Nanson GC & $\begin{array}{l}\text { University of Wollongong, Dept Geology, } \\
\text { Wollongong, Australia }\end{array}$ & 5 & 753 \\
\hline 7 & Dopita MA & $\begin{array}{l}\text { Australian National University, Institute of } \\
\text { Advanced Studies, Australia }\end{array}$ & 7 & 744 \\
\hline 8 & Hiller RG & $\begin{array}{l}\text { Macquarie Univ, Dept Biological Science, } \\
\text { Australia }\end{array}$ & 11 & 731 \\
\hline 9 & Bak T & $\begin{array}{l}\text { University of New South Wales, Scheme of } \\
\text { Material Science \& Engineering, Australia }\end{array}$ & 4 & 729 \\
\hline 10 & Salmon J & $\begin{array}{l}\text { Deakin University, Centre for Physics Act \& } \\
\text { Nutrition Research, Australia }\end{array}$ & 8 & 726 \\
\hline 11 & Sorrell CC & $\begin{array}{l}\text { University of New South Wales, Scheme of } \\
\text { Material Science \& Engineering, Australia }\end{array}$ & 2 & 721 \\
\hline 12 & Rekas M & $\begin{array}{l}\text { University of New South Wales, Scheme of } \\
\text { Material Science \& Engineering, Australia }\end{array}$ & 1 & 708 \\
\hline
\end{tabular}

Note: TR- Total records, TC- Total citations 


\section{Identification of core Journals in Energy and Environment Research}

Table 5 shows the counting ranking based core journals in energy and environment totally covered 1199 journals but, for analysis, we have selected only top 22 highly productive journals with more than 13 scientific papers. The results reveal that based on the literature outputs, PLOS One is in the top ranked with $11 \mathrm{~h}$-index and 46 records and the citations are 384, and followed by Astrophysical Journal is the next position with 44 articles with 1614 citations and h-index is 21, Monthly Notices of the Royal Astronomical Society is occupied in the third rank with 38 articles (=1389 citations, 11 h-index), Journal of Coastal Research (=28, 350 citations, 11 h-index), Renewable Energy (=28, 180 citations, 8 h-index), Astronomy \& Astrophysics (=25, 730 citations, 13 h-index), Journal of Experimental Biology (=23, 563 citations, 13 h-index), Physical Review B (=23, 616 citations, 13 h-index), Energy Policy $(=19,242$ citations, 7 h-index) and Energy and Buildings (=17, 184 citations, 6 h-index). It finds out from the analysis that more citations among the journals occupied by Monthly Notices of the Royal Astronomical Society (=1389 citations) and followed by Astrophysical Journal (=1614 citations).

Table 5: Ranking of Journals on Energy and Environment Research in Australia

\begin{tabular}{|c|l|r|r|c|}
\hline Sl. no & \multicolumn{1}{|c|}{ Journal } & TP & TC & R \\
\hline 1 & PLOS One & 46 & 384 & 1 \\
\hline 2 & Astrophysical Journal & 44 & 1614 & 2 \\
\hline 3 & Monthly Notices of the Royal Astronomical Society & 38 & 1389 & 3 \\
\hline 4 & Journal of Coastal Research & 28 & 350 & 4 \\
\hline 5 & Renewable Energy & 28 & 180 & 4 \\
\hline 6 & Astronomy \& Astrophysics & 25 & 730 & 5 \\
\hline 7 & Journal of Experimental Biology & 23 & 563 & 6 \\
\hline 8 & Physical Review B & 23 & 616 & 6 \\
\hline 9 & Energy Policy & 19 & 242 & 7 \\
\hline 10 & Energy and Buildings & 17 & 184 & 8 \\
\hline 11 & Journal of Physical Chemistry B & 17 & 761 & 8 \\
\hline 12 & Marine Geology & 17 & 441 & 8 \\
\hline 13 & Minerals Engineering & 17 & 238 & 8 \\
\hline 14 & Renewable \& Sustainable Energy Reviews & 17 & 237 & 8 \\
\hline 15 & Australian Journal of Experimental Agriculture & 15 & 231 & 9 \\
\hline 16 & Building and Environment & 15 & 178 & 9 \\
\hline 17 & International Journal of Hydrogen Energy & 15 & 841 & 9 \\
\hline 18 & Australian Journal of Agricultural Research & 14 & 209 & 10 \\
\hline 19 & Australian Journal of Earth Sciences & 14 & 164 & 10 \\
\hline 20 & Journal of Zoology & 14 & 185 & 10 \\
\hline 21 & Proceedings of the National Academy of Sciences & 14 & 902 & 10 \\
\hline 22 & Sedimentary Geology & 14 & 267 & 10 \\
\hline
\end{tabular}

Note: TP- Total publications, TC- Total citations, R-Rank

\section{Bradford law of scattering}

In 1934, Samuel Clement Bradford introduced the Bradford's law of scattering to test the journals outputs whether they are fit or not fit as per the production. The Bradford's law is to explain that a group of journals could be arranged in an order of decreasing productivity and revealed that journals which yield the most productive articles are coming first and the most unproductive in the last. According to this law, the journals are to be grouped into a number of zones each producing a similar number of articles. 
However, the number of journals in each zone will be increasing speedily. Then the relationship between the zones is $1: \mathrm{n}$ : $\mathrm{n} 2$. For describing the scattering phenomena, the following formula has been adopted by the researchers.

$\mathrm{F}(\mathrm{X})=\mathrm{a}+\mathrm{b} \log \mathrm{X}$

Where $F(X)$ - is the cumulative number of references as contained in the first-x most productive journal and ' $a$ ' and ' $b$ ' are constants. Total number of journals for this present study is 1199 .

Table 6: Bradford law of scattering in journals of energy and environment

\begin{tabular}{|c|c|c|c|c|c|c|c|c|}
\hline Sl. no & NJ & CJ & NA & TA & CA & Log of CJ & PCA & PCJ \\
\hline 1 & 1 & 1 & 46 & 46 & 46 & 0 & 1.64 & 0.08 \\
\hline 2 & 1 & 2 & 44 & 44 & 90 & 0.693 & 3.21 & 0.16 \\
\hline 3 & 1 & 3 & 38 & 38 & 128 & 1.098 & 4.57 & 0.25 \\
\hline 4 & 1 & 4 & 28 & 28 & 156 & 1.386 & 5.57 & 0.33 \\
\hline 5 & 1 & 5 & 28 & 28 & 184 & 1.609 & 6.56 & 0.42 \\
\hline 6 & 1 & 6 & 25 & 25 & 209 & 1.791 & 7.46 & 0.50 \\
\hline 7 & 1 & 7 & 23 & 23 & 232 & 1.946 & 8.28 & 0.58 \\
\hline 8 & 1 & 8 & 23 & 23 & 255 & 2.079 & 9.10 & 0.66 \\
\hline 9 & 1 & 9 & 19 & 19 & 274 & 2.197 & 9.78 & 0.75 \\
\hline 10 & 5 & 14 & 17 & 85 & 359 & 2.639 & 12.81 & 1.16 \\
\hline 11 & 3 & 17 & 15 & 45 & 404 & 2.833 & 14.42 & 1.41 \\
\hline 12 & 5 & 22 & 14 & 70 & 474 & 3.091 & 16.92 & 1.83 \\
\hline 13 & 3 & 25 & 13 & 39 & 513 & 3.218 & 18.31 & 2.08 \\
\hline 14 & 5 & 30 & 12 & 60 & 573 & 3.401 & 20.45 & 2.50 \\
\hline 15 & 3 & 33 & 11 & 33 & 606 & 3.496 & 21.63 & 2.74 \\
\hline 16 & 5 & 38 & 10 & 50 & 656 & 3.637 & 23.41 & 3.16 \\
\hline 17 & 8 & 46 & 9 & 72 & 728 & 3.828 & 25.98 & 3.83 \\
\hline 18 & 17 & 63 & 8 & 136 & 864 & 4.143 & 30.84 & 5.24 \\
\hline 19 & 12 & 75 & 7 & 84 & 948 & 4.317 & 33.83 & 6.24 \\
\hline 20 & 18 & 93 & 6 & 108 & 1056 & 4.533 & 37.69 & 7.75 \\
\hline 21 & 39 & 132 & 5 & 195 & 1251 & 4.883 & 44.65 & 11.0 \\
\hline 22 & 42 & 174 & 4 & 168 & 1419 & 5.159 & 50.64 & 14.50 \\
\hline 23 & 82 & 256 & 3 & 246 & 1665 & 5.545 & 59.42 & 21.34 \\
\hline 24 & 194 & 450 & 2 & 388 & 2053 & 6.109 & 73.26 & 37.53 \\
\hline 25 & 749 & 1199 & 1 & 749 & 2802 & 7.089 & 100 & 100 \\
\hline
\end{tabular}

NJ- No of journals, CJ- Cumulative journal, NA- No of articles, TA-Total article, CACumulative articles, PCA-Percentage of Cumulative articles, PCJ-Percentage of Cumulative journals

Table 6 indicates the journal distribution of research in the field of energy and environment in Australia. The Bradford's law of scattering was introduced by Samuel Clement Bradford (1934) and pointed out that if scientific journals are arranged in order to decreasing productivity of articles on a given subject, they may be divided into a nucleus of periodicals more particular devoted to the subject and several groups and zones contain the same number of articles as the nucleus when the number of periodicals in the nucleus and succeeding zones will be 1: n: n2. 


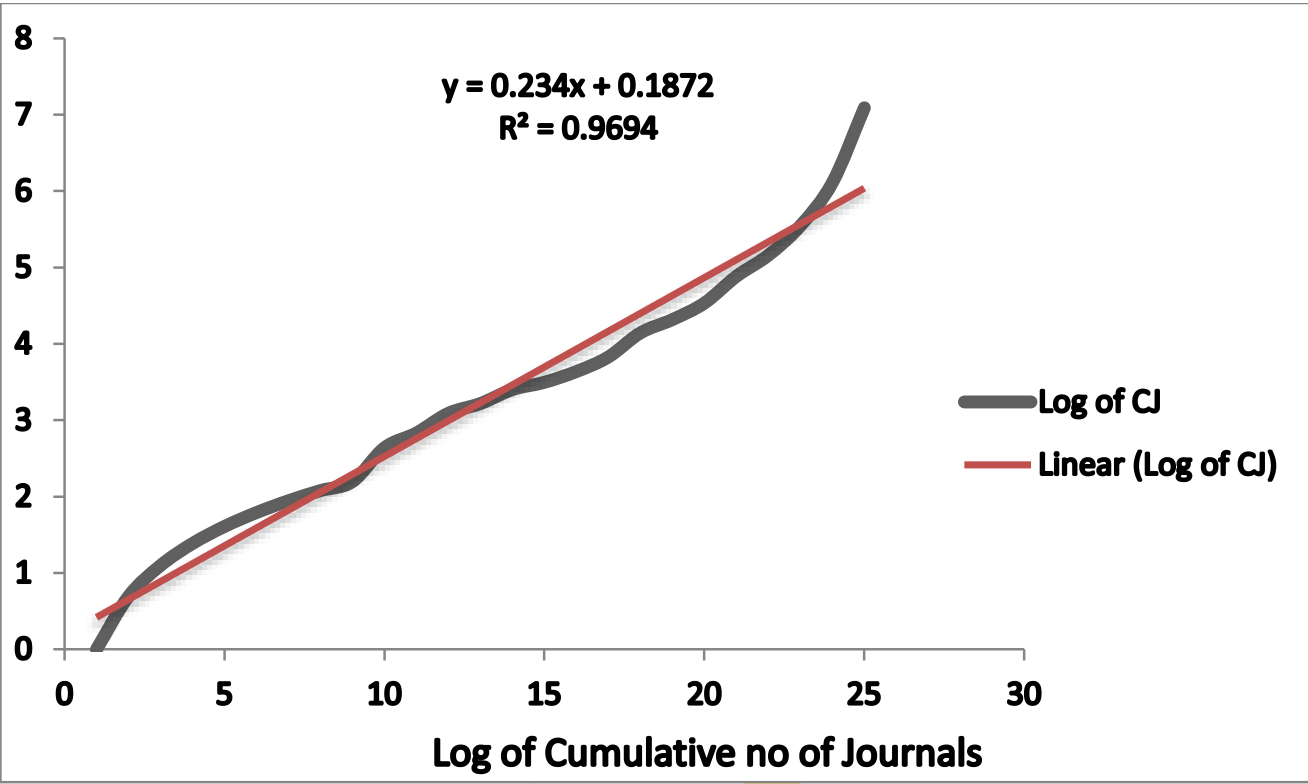

Graph 1: Log value of cumulative scientific journals

Based on the above table graph has been plotted with value of $\mathrm{R} 2=0.9694$ and also identified the Log value equation $y=0.234 x+0.1872$ to estimate the cumulative value of scholarly publications in energy and environment research.

Table 7: Zone wise distribution

\begin{tabular}{|c|c|c|c|c|c|}
\hline Zone & TJ & TJ \% & TA & TA \% & Multiplier \\
\hline 1 & 63 & 5.25 & 864 & 30.83 & - \\
\hline 2 & 193 & 16.10 & 801 & 28.59 & 3.06 \\
\hline 3 & 943 & 78.65 & 1137 & 40.58 & 4.89 \\
\hline Total & 1199 & 100 & 2802 & 100 & $3.975(\mathrm{mv})^{*}$ \\
\hline
\end{tabular}

TJ-Total Journals, TJ- percentage, TA- Total articles, TA - percentage, ${ }^{*}$ Mean value

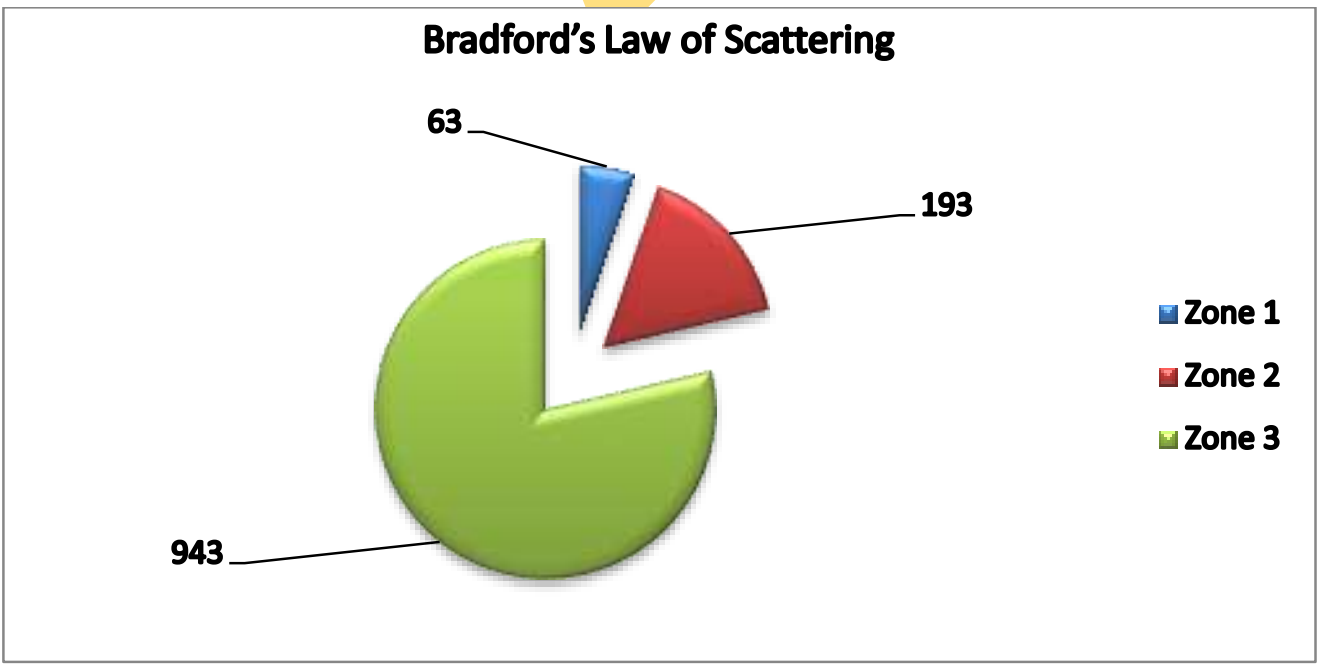

Figure 4: Bradford's Law of Scattering 
Table 7 and Figure 4 represents that the distribution of scholarly journals and contribution of articles have classified into three zones. According to Bradford, the zones, indicated will form an approximately geometric series in the form 1: n: $n 2$. But, it is identified that the relationship of each zone in the present study is 63:193:943. The ratio depicts that it does not fit into the Bradford's law of distribution. The results show that the distributions of core journals were published by a few numbers of journals. It finds here from the analysis, 63 refer to the number of journals in the Nucleus and the mean Bradford multiplier is 3.975 .

Hence, expression can be given as:

63:63x (3.975):63x (3.975) $2:: 1: n: n^{2}$

63:250.425:995.439375>1308.864

$\%$ error $=\frac{1308.864-1199}{1199} \times 100=9.163$

It is therefore, very clear that the percentage of error is so high and therefore, the data does not fit in Bradford's law.

\section{CONCLUSION}

The Bradford of scattering is one of the best test tools for scholarly publications in the field of Library and Information Science. In this present study, authors have applied to test the Law whether it is fit or not as per data output during the period of study. Therefore, we can conclude from the study in the field of energy and environment in Australia and the findings show that the global publications the share of Australia during 1991-2015 was 3.828183 which have gradually increased from 2.277657 in 1991 to 4.756022 in 2015 . Based on the study, the results reveal that the distributions of core journals were published by a few numbers of journals. It finds from the analysis, 63 refer to the number of journals in the Nucleus and the mean Bradford multiplier is 3.975. It identifies the relationship of each zone in the present study is 63:193:943. The ratio depicts that it does not fit into the Bradford's law of distribution. Moreover, the percentage of error is so high that the data does not fit in Bradford's law. Some number of scientometric studies have previously done in various fields by researches and scientists, this scientometric analysis on energy and environment research of Australia, authors hope this study may generate more scientometric studies for the resolution of evaluating energy and environment research in the country.

\section{RefERENCES}

Arjun Lal, Panda, K.C. 1999. "Bradford's Law and its Application to Bibliographical of Plant Pathology Dissertations: an analytical approach." Library Science with Slant to Documentation and Information Studies 36(3): 193-206.

Asai, I. 1981. "A General Formulation of Bradford's Distribution: the graph oriented approach." Journal of American Society for Information Science 32(2): 113-119.

ASSAf (2006). "Report on Strategic Approach to Research Publishing in South Africa", Academy of Sciences of South Africa, Pretoria.

Avramescu, A. 1980. "Theoretical Foundation of Bradford's Law." International Forum of Information Documentation 5: 15-22.

Bandyopadhyay, A. 1999. "Bradford's Law in Different Disciplines." Annals of Library Science and Documentation. 
Bradford, S.C. 1934. "Sources of Information on Specific Subjects." Engineering 137(3550):85-86.

Brookes, B.C. 1977. "Theory of Bradford's Law." Journal of Documentation 33(3): 180-209.

Drott, C.M. 1981. "Bradford's Law : theory, empiricism and the gaps between." Library Trends 30(1): 42-52.

Egghe, L. 1986. "The Dual of Bradford's Law." Journal of American Society for Information Science 37: $173-89$.

Egghe, L. 1990. "Application of the Theory of Bradford's Law to the Calculation of Leimkuhler's Law and the Completion of Bibliographies." Journal of American Society for Information Science 41(3): 204-09.

Gupta, B.M. (1980). “A citation analysis of internal and external connections of a research branch: A case study of solar energy research in the USSR", Annals of Library Science and Documentation, 27, 14.

Gupta, D.K. 1991. "Application of Bradford's Law to Citation data of Ethiopian Medical Journal." Annals of Library Science and Documentation.

Lawani, S.M. 1973. "Bradford's Law and the Literature of Agriculture." International Library Review 5(3): 341-50.

Lawson, J; Kostrewsi, B, and Oppenheim, C. (1980). “A Bibliometric study on a new subject field: energy analysis", Scientometrics, 2, 3, pp. 227-237.

Nicolaisen \& Hjorland. 2007. "Practical Potentials of Bradford's: a critical examination of the received view." Journal of Documentation 63(3): 359-77.

Pouris, A \& Pouris, A. (1987). “Structure of Energy Related Literature: An Application of Citation Analysis. South African J. Sci., 83, pp. 138-142, 1987.

Qui, L. 1990. "An Empirical Examination of the Existing Model for Bradford's Law." Information Processing and Management 26(5): 655-72.

Ravichandra Rao, I.K. 1998. "An Analysis of Bradford Multipliers and a Model to Explain Law of Scattering." Scientometrics 41(1-2): 93-100

Tijssen, R.J.W. (1992). "A Quantitative Assessment of Interdisciplinary Structures in Science and Technology: Co Classification Analysis of Energy Research", Res. Policy, 21, 1, $27-44$.

Tyagi, A.K. 1986. "Bradford's Law and its Application to Study Citation Frequency of Bibliographical Data of Indian Journal of Physics." ILA Bulletin 21(3-4): 90-95.

Velmurugan, C \& Radhakrishnan, N. (2014). "Publication Research Trends on Technical Review Journal: A Scientometric Study", International Journal of Digital Library Services (IJDLS), 4, 3, 45-55.

Velmurugan, C \& Radhakrishnan, N. (2015). "A Scientometric Analysis of Research Papers Published on Pharmacognosy as reflected in the Web of Science". Advances in Pharmacognosy and Phytomedicine, 1, 1, 27-40.

Velmurugan, C \& Radhakrishnan, N. (2015). "Authorship trends and collaborative research work on Library Herald: a Scientometric analysis", Somvir, Information Science and Digital Libraries, International Research Publication House, Delhi.

Velmurugan, C \& Radhakrishnan, N. (2015). "Journal of Information Literacy: A Scientometric Profile", Journal of Information Sciences and Application, 3, 1, 1-9.

Velmurugan, C \& Radhakrishnan, N. (2015). "Literature output of Supply Chain Management: A Scientometric approach", Journal of Organizational Behaviour, 3, 2, 31-44.

Velmurugan, C \& Radhakrishnan, N. (2015). "Quantitative Analysis of Scientific Publications Output on Engineering Journal: A Scientometric Study", Journal of Information Sciences and Application, 3, 1, 19-30.

Velmurugan, C \& Radhakrishnan, N. (2015). "Research analysis by means of Scientometric techniques on Biotechnology", International Journal of Multidisciplinary Consortium (IJMC), 2, 1, 256-265.

Velmurugan, C \& Radhakrishnan, N. (2015). "Scientometric observations of Authorship Trends and Collaborative Research on DESIDOC Journal of Library and Information Technology", Collnet Journal of Scientometrics and Information Management, 9, 2, 193-204, DOI: 10.1080/09737766.2015.1069957. 
Velmurugan, C. (2013). “Bibliometric analysis with special reference to Authorship Pattern and Collaborative Research Output of Annals of Library and Information Studies for the Year 2007 2012". International Journal of Digital Library Services, 3, 3, 13-21.

Velmurugan, C. (2013). "Research Trends in Journal of Intellectual Property Rights (JIPR): A Bibliometric Study", Library Philosophy and Practice (e-journal), Paper 1043. http://digitalcommons.unl.edu/libphilprac/1043.

Velmurugan, C. (2013). "Scientometric analysis: Annals of Library and Information Studies Publications Output during 2007-2012", International Journal of Library and Information Studies, 3, 3, 58-65.

Velmurugan, C. (2014). "Research Trends in Indian Journal of Pure and Applied Physics (IJPAP) for the Year 2009 - 2012", Asian Review of Social Sciences, 3, 1, 24-28. 